\title{
Advantages and Development Strategies of Sports Tourism in Guizhou Province under the Background of "Belt and Road" Strategy
}

\author{
Chen Linong, Zhao Hong \\ Graduate Department of Guangzhou Sport University \\ Guangzhou 510500
}

\begin{abstract}
This paper analyzes the characteristics of sports tourism from the perspective of tourism development in Guizhou Province, and teases out the significant impact of the characteristic sports tourism of Guizhou Province on the development of tourism, and explores the strategies for the development of sports tourism in Guizhou. It adopts scientific research methods such as literature review, expert interviews, field research, and logical analysis. Through collaborative development, and integration with the outside world, it explores the advantages of sports tourism resources to clarify the development strategy by grasping the opportunity to promote infrastructure interconnection under the "Belt and Road" strategy. It will provide reference for the development of sports tourism industry in Guizhou Province and the creation of sports tourism resources.
\end{abstract}

Keywords-"Belt and Road"; Guizhou sports tourism; collaborative and joint development; advantages; development strategy.

\section{INTRODUCTION}

Located in the southwest China, Guizhou Province is an important land and sea transportation junction for domestic economy and culture to go abroad towards south and southwest Asia. It is one of the important provinces for constructing the Maritime Silk Road Economic Belt and the Land Silk Road. On July 6, 2017, the China National Tourism Administration and the General Administration of Sport of China held the National Sports Tourism Industry Development Conference and jointly released the "Belt and Road" Sports Tourism Development Action Plan, proposing the strategic objectives for the common development of the sports and tourism industries, in order to create a new industrial structure program [1]. "Belt and Road" initiative is an important strategy for China's economy, culture, and politics going global and attracting others'. Guizhou, a major province of tourism in the southwest region, should be supported by national policies in economy, culture, and society. In recent years, sports tourism, as a lifestyle and activity integrating leisure tourism and fitness tourism, has become popular with the public, and the consumption on it has become more and more normalized. The unique product characteristics and service characteristics of sports tourism have exerted great influence on the development of tourism, which has become more and more obvious. This article explores the characteristics of sports tourism from the perspective of tourism development in Guizhou Province, carefully sorts out the significant impact of Guizhou's characteristic sports tourism on tourism development, and explores the strategy of sports tourism development in Guizhou, which provides reference for Guizhou Province in the upcoming development of the sports tourism industry and the creation of sports tourism resources.

\section{GUIZHOU IN THE BELT AND ROAD STRATEGY}

The "Belt and Road" development strategy was proposed by Chairman Xi Jinping during his visit to Central Asia and Southeast Asian countries, short for the "Silk Road Economic Belt" and "21st Century Maritime Silk Road". Taking the ancient "Silk Road" and holding high the banner of peaceful development, we actively build economic partnerships with countries along the routes, and build a community of shared interests, destinies, and responsibilities with political mutual trust, economic integration, and cultural tolerance. [3] In the "Vision and Actions on Jointly Building Silk Road Economic Belt and 21st-Century Maritime Silk Road”, the Chinese government has clearly stated that we should take advantage of the location advantages of Guangxi Province and Southeast Asian countries, speed up the development of sea and waterway traffic in the southwest, in order to work with them to create a regionally international transportation hub. To serve as a strategical support for the open up and development of the southwest and south central regions, Guizhou, located in the southwest China, bordering Guangxi to the south and Yunnan to the southwest, is an important transportation hub for the development of central China to the southwest region, and also a major thoroughfare linking the central and northern regions with the Southeast Asian countries. We should give full play to the advantages of Guizhou Province and promote the construction of the transport corridors connecting the neighboring provinces, and create a new regional economic cooperation area in Guizhou, making it an economic sports tourism radiation center facing the southwest and south China. People have paid more attention to that how does Guizhou use the advantages of the national "Belt and Road" policy and sports tourism, thenew sports industry to develop its economy, publicize its culture, and build a civilized city. 


\section{THE ROLE AND OPPORTUNITY OF SPORTS TOURISM IN THE BELT AND ROAD STRATEGY}

The "Belt and Road" initiative aims to realize China's modernization by 2020 and build a moderately prosperous society in an all-round way. In the period of development and also the window period under the new normal, Guizhou opens up and develops, making itself a pivotal gateway in the 21st century Maritime Silk Road and Silk Road Economic Belt. To achieve a well-off society in nationwide by 2020, Guizhou must accelerate its development. In the strategy of the "Belt and Road”, it is Guizhou's unique advantage that steps up the development of sports tourism. We deeply dig the indigenous culture, geography, climate, humanity and other resources, elaborately engineer and conduct the branding strategy of Colorful Guizhou, as well as use a series of theme activities to publicize Guizhou and expand its influence. In these ways, we build a vivid image of "Colorful Guizhou", intensify the differentiation among all tourist products and highlight the competitive edge of its sports tourism. Therefore, we can realize the mixture and progress of culture, agriculture, industry and tourism. Undoubtedly, we can further propel the sports tourism of Guizhou by actively participating in and following the Belt and Road initiative.

\section{THE ADVANTAgES AND STATUS OF SPORTS TOURISM IN Guizhou Province under the BeLt and RoAd initiative}

\section{A. Policy}

On July 7, 2017, the General Administration of Sport of China and the China National Tourism Administration jointly proposed the "Belt and Road" Sports Tourism Development Action Plan (2017-2020), in which the sports tourism is regarded as a new industry form generated by combination of the sports industry and the tourism industry. The development of sports tourism is an indispensable requirement for enriching the tourism product system, expanding tourism consumption, and promoting the transformation and upgrading of tourism. It is also an inevitable choice to revitalize sports resources, integrate national fitness and national health, and promote the quality and efficiency of the sports industry. It is of great significance to nurture new economic development engine and expand economic development. At the end of 2016, Guizhou Province released the "13th Five-Year Plan for Sports Development in Guizhou Province" [1], proposing that Guizhou should take mountain outdoor sports and water sports as the breakthrough point, take traditional ethnic sports as the focal point, grasp sports events, vigorously cultivate new sports forms, implement a brand strategy of sports, and build a great and powerful province with mountainous ethnic sports. Ethnic minority sports tourism in Guizhou Province exactly meets this requirement, providing multiple choices for tourists' routes, and also increasing tourists' return rates, and thus increasing the added value of tourism resources. The inevitable trend of ethnic minority and tourism development coincides with the strategy of "Belt and Road" to create exquisite tourism routes and project strategies.

\section{B. Climate}

Guizhou sits on the Yunnan-Guizhou Plateau, with an average elevation of more than 1,000 meters. The average annual temperature in most areas of the province ranges from $12^{\circ} \mathrm{C}$ to $17^{\circ} \mathrm{C}$, and the average temperature in the hottest months of the summer is below $28{ }^{\circ} \mathrm{C}$. Belonging to the subtropical humid monsoon climate zone, Guizhou is affected by the southwest monsoon, and the annual precipitation is abundant. It is a good summer resort as the average annual temperature varies in a small range, and the climate is fairly mild in winter and rather cool in summer. The cooler summer in the Guizhou Plateau will become an advantage for its tourism development as the global warming goes on. Since geological resources of tourism are closely related to geological process and geological bodies, and most of them are formed in the long geological history, they are also spatially localized, temporally sustainable, morphologically nonrenewable and scientifically recognized.

\section{Ecological culture}

The tourism resources and products of Guizhou Province have unique features, mainly centering on the original ecological culture. The development of unique rural tourism enables ethnic minority cultures to be well inherited and protected. During the "Twelfth Five-Year Plan" period, the high-speed railway and expressway leading to Guizhou were built one after another, providing convenience for tourists from other provinces. At the same time, the number of short trips in the province has also increased significantly. More importantly, along with the intensified implementation of the urbanization, characteristic towns and sports tourism towns will come into being. The Yushe National Forest Park in Liupanshui hosts outdoor sports in summer, and operates as International Ski Resort in winter. Last year, the province's rural tourism has received a total of 56.055 million tourists, accounting for $32.9 \%$ of the total number of tourist reception; the village tourism revenue of 22.14 billion yuan accounting for $15.5 \%$ of total tourism revenue; nearly 1.05 million people have gained jobs in rural areas. The number of people who have benefited from the tourism industry, have reached more than 3 million. About $15 \%$ of the province's urban per capita net income comes from the tourism industry [5]. Rural sports tourism brings benefits to the people and makes Guizhou villages more beautiful.

\section{Geographic conditions}

TABLE I. SPORTS TOURISM EVENTS IN VARIOUS AREAS OF GUIZHOU PROVINCE

\begin{tabular}{|c|c|}
\hline City/Areas & Items \\
\hline Liupanshui & Kayak silent water championship ,International Marathon in Summer,Ski Festival \\
\hline Guiyang & IAAF World Cross Country Championships, Summer Marathon \\
\hline Zunyi & $\begin{array}{r}\text { Lou shanguan · hailongtun international mountain outdoor competition, which covers cross-country } \\
\text { running, directional cross-country running, mountain bike, weight-bearing mountain climbing }\end{array}$ \\
\hline
\end{tabular}




\begin{tabular}{|c|c|}
\hline \multicolumn{2}{|r|}{ Cont.to TABLE I } \\
\hline Anshun & The river rock climbing \\
\hline Tongren & $\begin{array}{c}\text { Round Mount Fanjing International Road Cycling Invitational Tournaments, Mount Fanjing Climing } \\
\text { Competition,Dragon Boat Raing }\end{array}$ \\
\hline Bijie & Cross-country running, Mountain marathon, Mountain bike, Hiking \\
\hline $\begin{array}{c}\text { Buyi and Miao } \\
\text { Autonomous Prefecture } \\
\text { of QianNan }\end{array}$ & Top, Dragon boat, Horse racing、Stilts racing, Cuqiu activity \\
\hline $\begin{array}{l}\text { Qiandongnan Miao and } \\
\text { Dong Autonomous } \\
\text { Prefecture }\end{array}$ & $\begin{array}{c}\text { Single-Bamboo Floating Invitational Tournaments, "Top of the Leigong mountain in Summer Bala } \\
\text { River”Cycling Climbing Racing, Racing in Southeastern Guizhou Contention for OX king, Cockfight, } \\
\text { Bird fight, Pig fight,Car racing with } 24 \text { bends }\end{array}$ \\
\hline
\end{tabular}

The territory of Guizhou Province is dominated by Plateau Mountains, with west higher than east.

Its altitudes are tilted from the centre to the north, east and south. At 2900 meters above sea level, Jiucaiping, in Liupanshui city, is Guizhou's highest point. Due to the high altitudes, Liupanshui city has two lowest ski slopes in China, namely Meihuashan International Ski Resort and Yushe International Ski Resort. In the southern part of Guizhou province, the lowest valley is only 137 meters and the water flow is concentrated. Therefore, it is conducive to various water sports such as the annual invitational tournament of bamboo drift movement in Southwest Guizhou Autonomous Prefecture. The average altitude of the whole province is about 1000 meters. The landforms can be classified into three types: plateaus, hills and basins. The plateaus account for $87 \%$ of the whole area, the hills account for $10 \%$, and the basin is $3 \%$. There is Dalou Mountain in the north, Miao Ridge in the centery and southern part, Wuling Mountain in the northeast, and Wumeng Mountain in the west [6]. At present, all regions in Guizhou province make full use of natural geographical advantages, unique topography and landforms. Guizhou province also integrates own development characteristics and carries out various outdoor sports activities according to local conditions. These actions have attracted a large number of tourists and provided various sports tourism events convenience (Table 1).

\section{THE PRACTICAL DIFFICULTY OF DEVELOPING SPORTS TOURISM IN GUIZHOU}

\section{A. Weak economy and poor infrastructure}

Guizhou, with a relatively weak economic foundation, is located in the southwest China. As the economic base determines the superstructure, the economic backwardness hinders the development of all other activities in Guizhou. The economy of Guizhou Province has developed in recent years, even faster than that of the developed regions. However, due to its small scale, it is still lagging behind. In the 2017 annual national economic rankings, Guizhou Province still ranks at the bottom of the country. Whether tourism or sports tourism, they both belong to cultural construction and cultural construction belongs to superstructure. Furthermore, the sluggish economic development in Guizhou and the insufficient funds fail to contribute too much in infrastructure construction for sports tourism. The poor infrastructure will become one of the major obstacles to the development of sports tourism.

\section{B. Backward Education}

The education in Guizhou is lagging behind, which can be seen in two aspects, that is, its weak economy and people's thinking. Without enough economic support, the investment in education is can't be guaranteed. What's more, there still exist the people who live in some parts of Guizhou believing in the idea that study is useless. Therefore, we can say that the education hasn't been running well for a long time because people are not willing to invest in themselves. Talent matters most. In the development of the sports tourism industry, sports tourism has its special nature and needs specific professionals. What's more, talents account for a large proportion of the factors constraining the development of sports tourism in Guizhou. And the development of sports tourism requires versatile talents who both understand the development and research of the sports tourism market and are familiar with the sports industry and tourism operations. At present, there is no college in Guizhou that sets sports tourism majors to cultivate comprehensive talents in sports tourism.

\section{Complicated natural environments and difficulty in developing resources}

The landform of Guizhou Province belongs to the western plateau mountain. There are many mountainous regions, topographically high in the west and low in the east. Due to the influence of climate and topography, natural disasters occur frequently in the province. Floods, droughts, hailstorms and low-temperature freezing are increasingly aggravated. The potential hazards of geological disasters such as landslides, mudslides and rock collapses have increased, showing an upward trend. Natural disasters have become one of the critical factors that restrict the economic and social development of our province and people's production and life. For Guizhou Province, natural tourism resources occupy a major part in the development of tourism resources, but the complex geographical environment makes it more difficult to develop tourism resources.

\section{THE DEVELOPMENT STRATEGY OF SPORTS TOURISM IN GUIZHOU PROVINCE UNDER THE BACKGROUND OF BELT AND ROAD}

\section{A. Taking a coordinated development, both bringing in and going out}

According to the characteristics and location of ethnic sports tourism resources in Guizhou Province, it is necessary to 
fully rely on the tourism belt of the Silk Road, firmly seize the opportunity of promoting infrastructure interconnection under the "Belt and Road" strategy, intensify the exploration of the advantages of national sports tourism resources, and follow the joint development path [4]. For example, we have forged a joint development chain of sports tourism by combining the geographic advantages of Yunnan, Guangxi, and Sichuan, enabling each province to develop its advantages, highlights its own characteristics, which attracts more domestic and foreign tourists to travel and go sightseeing in these places. By doing this, we not only promote the development of sports tourism, but also enhance economic and cultural exchanges between provinces, thereby increasing the local residents' income and raising their living standards. Only by conducting coordinated and joint development among provinces, can we enhance the level of facilitation of sports tourism and actively develop the unique location advantages and potential resource in the "Belt and Road" of each province in southwest China. And the complementarity among the provinces, cities and the districts actively can be improved, as well as the exchanges among the ethnic minority cultures so as to maximize the capacity of various resources. To go abroad, the sports tourism can rely on official departments, social organizations, enterprises, and personnel exchanges. [8] The advanced sports management and techniques are what we should learn from foreign countries and other provinces to apply to the same or similar sports tourism areas in the province, so as to promote their own development, and accelerate the localization of advanced management in the local community.

\section{B. Launching sports events in scenic areas to promote local economic development}

Guizhou Province is rich in tourism resources, but the development of sports tourism resources is still in the prototype stage. Among the sports tourism products that have been developed, the majority are the activate sports tourism products, namely the event-type sports tourism products. In summer, the Asian Cross-Country Championship and the first track and field endurance item in plateau region were successfully held in Qingzhen City. The Nanjiang Grand Canyon has also undertaken the China-Guyin International Natural Water Rafting Competition. There are also many events like Liupanshui City's annual plateau marathon, the mountain bike competition held in Jinyang New Areas, and the National Rowing Winter Championships in Hongfeng Lake Water Sports Training Base of Qingzhen City held the 2018. In winter, the Flatwater Kayaking Championship has been launched in Liupanshui. These activities not only enhance the cultural taste and brand of the city, but also serve as an important carrier and display platform for Guizhou's unique culture, and promote the local economic development.

\section{Adhering to development while taking care of ecology}

In the process of developing sports tourism, Guizhou Province should focus on the development and ecology. It should make much more efforts on the development of the colorful Guizhou mountain parks and enable the government's tangible hands to actively cooperate with the market's invisible hand to promote the regional tourism, multicultural protection and inheritance, ecological and environmental protection, while advancing the construction of the characteristic towns. We need to protect ecological environment, publicize culture, and promote economic growth and social harmony. When creating brand names for sports tourism, local governments must not only meet the visual requirements of our visitors, but also satisfy our physical and mental needs. They should follow a high-end, green, and intensified development with its characteristics and integrate the good eco-tourism environment with an ever-growing cultural and sports industry to create more wealth for the people in the province and improve their live standards. With all these efforts, we can make the ecological rural tourism and outdoor sports, the concept of lowcarbon leisure sports tourism more popular in Guizhou Province.

\section{Strengthen publicity and train professional sports tourism talents}

We need to actively carry out sports tourism propaganda along the "Belt and Road" and make use of the media and networks. The Liupanshui International Marathon costs 5 million yuan per year on CCTV live broadcast. We should launch sports and cultural activities in the provinces along the "Belt and Road", support sports and tourism games by the funds allocated by the General Administration of Sport of China and the China National Tourism Administration. We should launch sports events according to the conditions of countries and regions along the route, give full play to the advantages of major regions, and build a sports event brand along the Belt and Road. The integration of the sports industry and the tourism industry requires both a large amount of funds and technology, and talents which is a key factor. If people who understand sports do not understand tourism, and those who understand tourism do not understand sports, it is difficult to coordinate the two industries [9]. Therefore, the government needs to strengthen the cooperation between the tourism and sports departments, build sports tourism training and practice structures, actively nurture sports and tourism professional and technical talents, and improve the service of the sports tourism industry in a modern society. Sports and tourism colleges across the country can set sports tourism management profession to train talents who can serve to improve the quality of sports tourism.

\section{CONCLUSION}

Today's sports tourism in Guizhou Province is attribute to its previous development, and will contribute to future prosperity. We studied sports tourism in Guizhou under the historical background of Belt and Road Initiative. In addition, by reorganizing and studying relevant materials as well as analyzing its advantages, this paper explores a new strategy that is in line with the development of sports tourism in Guizhou, so as to advance a new pattern of sports tourism communication. In conclusion, it is a must for flourishing of sports tourism in Guizhou to take the road of joint development, combine bring in and go out together, carry out sports competitions in scenic areas, actively drive local economic development, stick to two bottom lines of green development and protecting ecosystem, make efforts to create green and 
healthy sports tourism brand and increase publicity as well as cultivate professional talents.

\section{REFERENCES}

[1] Gao Pengchun. Research on the Development Strategy of National Sports Tourism in the Western Region against the Backdrop of "Belt and Road" Initiative [J]. Journal of Qujing Normal University, 2017, 36(04):22-24+38.

[2] Jiang Wei,Qu Jin. Study on Development Strategy of Coastal Sports Tourism in Guangdong under the Belt and Road Initiative [J]. Journal of Guangzhou Sport University, 2016, 36(06):61-64.
[3] Zheng Rui. Research on the Development Status of Guizhou Cultural Tourism Industry [J].Executive, 2013, 1(7): 1-2.

[4] World Touris m Organization Extolled the "Guizhou Model” of Rural Tourism”-Touris m, Rural Areas, Guizhou, Developmen,-Gu izhuo China http://www.chinaguizhou.gov.cn/system/2012/06/25/ 011503935.sht

[5] Wang Qianjing. Guizhou's Development Strategy Research under the "Belt and Road"[J]. Journal of Guizhou Commercial College, 2015, 28(04):43-46.

[6] Chen Gang. Research on Promoting International Communication of Sports Culture in the Implementation of "Belt and Road" Strategy [J]. Journal of Capital Institute of Physical Education, 2017, 29(01):4-7+25.

[7] Yang Qiang. The Dynamics and Mechanism of the Integration and Development of Sports Tourism Industry [J]. Journal of Physical Education, 2016, 23(04):55-62. 